\title{
PERCEPÇÃO DE USUÁRIOS DE ESPAÇOS PÚBLICOS DE CURITIBA, PARANÁ, SOBRE A PRESENÇA DE POMBOS (Columba livia)
}

(Perception of users of public places of Curitiba, Parana, on the presence of pigeons (Columba livia))

\author{
Camila Marinelli Martins ${ }^{1}$, Alexander Welker Biondo², Karina Francini Braga ${ }^{3}$, Simone \\ Tostes Oliveira ${ }^{4}$ \\ ${ }^{1}$ Depto. de Medicina Veterinária Preventiva e Saúde Animal - USP - São Paulo - Brasil \\ 2 Depto. de Medicina Veterinária - UFPR - Paraná - Brasil \\ ${ }^{3}$ Pontifícia Universidade Católica do Paraná - PUC-PR - Paraná - Brasil \\ ${ }^{4}$ Depto. de Medicina Veterinária - UFPR - Paraná - Brasil - Contato: tostesimone@gmail.com.br
}

RESUMO: Os pombos (Columba livia) no ambiente urbano são um problema de saúde pública devido aos agravos causados por eles. Este estudo avaliou a percepção das pessoas nas praças do centro de Curitiba, Paraná, em relação à presença de pombos. Foram entrevistados estudantes e servidores universitários, moradores, comerciantes e transeuntes com um questionário semiestruturado em 2012. Os entrevistados foram contra a presença dos pombos $(533 / 887,60,1 \%$, $p<0,01)$ e a proporção de mulheres contra foi maior do que a proporção de homens $(p=0,04)$. A maioria dos entrevistados considerou a quantidade de pombos exagerada $(617 / 887,69,6 \%, p=0,04)$ e $272 / 617(44,1 \%)$ atribuíram como causa a disponibilidade de alimento. 825/887 (93\%) afirmaram que pombos podem transmitir doenças. As principais afecções citadas foram doenças respiratórias (127/360, $35,3 \%$ ) e doenças causadas por piolhos ou pulgas (82/360, 22,8\%), o principal problema relatado foi a sujeira $(116 / 202,57,4 \%)$ e a ação mais aprovada para controle populacional foi a educação da população $(617 / 887,69,6 \%)$ por meio da televisão (273/887, 30,8\%). O estudo mostrou que pessoas que convivem com pombos nos centros urbanos não concordam com a presença dos mesmos e que as medidas para controlá-los são com as pessoas e não diretamente nos animais. Palavras-chave: centros urbanos; educação; fauna sinantrópica; saúde pública; zoonoses

ABSTRACT: The pigeons (Columba livia) in the urban environment are a public health problem due to injuries caused by them. This study evaluated the perception of people in the squares of Curitiba, Paraná downtown, for the presence of pigeons. In 2012, were interviewed students and university servers, residents, merchants and passersby with a semi-structured questionnaire. Respondents were against the presence of pigeons $(533 / 887,60.1 \%, p<0.01)$ and the proportion of women against was higher than the proportion of men ( $\mathrm{p}=0.04)$. Most respondents considered the amount of pigeons exaggerated $(617 / 887,69.6 \%, \mathrm{p}=0.04)$ and $272 / 617(44.1 \%)$ attributed as the cause food availability. $825 / 887(93 \%)$ informed that pigeons can carry disease. The main affections informed were respiratory diseases $(127 / 360,35.3 \%)$ and diseases caused by louse or fleas $(82 / 360,22.8 \%)$, the main problem reported was dirt $(116 / 202,57.4 \%)$ and the main action approved for population control was education of the population $(617 / 887,69.6 \%)$ through television $(273 / 887,30.8 \%)$. The study showed that people living with pigeons in urban centers do not agree with their presence and the measures to control are with people and not directly in the animals.

Key Words: education; public health; synanthropic fauna; urban centers; zoonoses 


\section{INTRODUÇÃO}

\section{Pombos domésticos (Columba} livia) são aves originalmente do continente europeu, introduzidos no Brasil no século XVI (Nunes,2003). Estes pombos estão em grande quantidade nos centros urbanos devido às condições da arquitetura urbana, com vãos e fissuras que favorecem o abrigo e a nidificação, favorecendo também o aumento desta população. Aliado a isso, há ausência de predadores naturais, como aves de rapina, e há alta disponibilidade de alimentos, haja vista que esses animais apresentam baixa exigência alimentar, podendo nutrir-se apenas da alimentação fornecida por seus admiradores (Nunes,2003; Schuller, 2005; Rodrigues et al., 2009). Várias doenças infecciosas podem ser adquiridas pelo o contato direto ou indireto com pombos, por isso a presença destas populações nos centros urbanos é considerado um problema de saúde pública (Rodrigues et al., 2009; Méndez et al., 2013). As doenças descritas como adquiridas diretamente de aves urbanas ou de seus habitats são: psitacose (ornitose), histoplasmose, campilobacteriose, micobacteriose, criptococose e salmonelose (GonzálezAcuña et al., 2007; Bonnefoy et al., 2008; Silva e Capuano, 2008; Costa et al., 2010; Dickx et al., 2010; Faria et al., 2010; Lima et al., 2011; Geigenfeind et al., 2012; Rocha-e-Silva, 2014). Algumas delas, como a criptococose, transmitida através da inalação de aerossóis de fezes secas contaminadas, podem levar à morte e o Estado do Paraná possui casos de óbitos registrados por esta causa (CRMV-PR, 2008; ACIL, 2013). Além destas afecções, os pombos podem albergar ectoparasitas como piolhos, pulgas e ácaros, podendo infestar os locais onde eles têm acesso, causando alergias e outras dermatopatias em pessoas e outros animais (Haag-Wackernagel e Spiewak, 2004; Bonnefoy et al., 2008).

As reclamações sobre a presença de fauna sinantrópica em Curitiba podem ser feitas por telefone pela população para uma central de atendimento da prefeitura e são repassadas ao Centro de Controle de Zoonoses e Vetores (CCZV) para que sejam investigadas e tomadas providências. Em levantamentos prévios e com dados fornecidos pelo CCZV, entre os anos de 2003 e 2012, os pombos foram a principal causa de reclamação $(23,6 \%)$, excluindo-se as reclamações por roedores que são registradas por outra via na cidade (Braga et al., 2009).

Apesar de serem considerados fauna sinantrópica, os pombos devem ter seu controle baseado primariamente em manejo ambiental, que não implique em mortandade populacional, segundo a Instrução Normativa IBAMA n 109, DE 3 de agosto de 2006. Assim, estratégias de controle devem ser baseadas em tentar eliminar os quatro "As", sendo eles: alimento, água, abrigo e acesso (CCZV, s.d). A normativa ainda prevê que em situações específicas de ameaça à saúde pública, a eutanásia dos pombos fica permitida para controle populacional. Entretanto, de forma geral, a captura e eliminação dos pombos não são estratégias eficientes, pois podem aumentar a população de outras espécies, levando a outros agravos, além de constituir-se um crime ambiental (Sguarizi, 2007).

Visando buscar subsídios para melhorar as políticas públicas em relação ao aumento populacional de pombos e suas consequências relativas a zoonoses e poluição ambiental, é importante que se investigue a percepção das pessoas de cada local sobre a presença destas aves. Para que medidas públicas educacionais sejam efetivas, é importante considerar a opinião e o conhecimento da população acerca do assunto. Desta forma, o 
presente estudo avaliou a percepção de usuários de espaços públicos e seu entorno, em relação à presença de pombos, no centro da cidade de Curitiba, Paraná, Brasil.

\section{MATERIAL E MÉTODOS}

\section{Área de estudo}

O presente estudo foi realizado na cidade de Curitiba, Paraná, região do Sul do Brasil. A região central da cidade tem praças, residências, lojas comerciais, hospitais e um dos campus da Universidade Federal do Paraná (Prédio Histórico-UFPR). Diariamente é observada uma grande quantidade de pombos nas praças, nas entradas dos estabelecimentos, eventualmente dentro destes, e em cima dos telhados. Para o presente estudo, foram escolhidas as praças Santos Andrade e Rui Barbosa e as ruas com frente para as mesmas, incluindo residências, lojas comerciais e o Prédio Histórico-UFPR.

\section{Coleta de dados}

Trata-se de um estudo transversal de entrevistas com questionário de perguntas fechadas e abertas, elaboradas com base em literatura sobre a superpopulação de pombos nos centros urbanos. Os entrevistados foram divididos em quatro categorias (1) transeuntes, (2) estudantes e servidores da UFPR, (3) moradores e (4) comerciantes do entorno das praças. Os comerciantes foram subdivididos de acordo com o tipo de comércio, sendo (a) comércio ambulante ou fixo de comida, (b) comércio de saúde e (c) outros.

O questionário abordou cinco grupos de questões: (1) demográfico (gênero e idade), (2) percepção individual (opinião quanto à presença de pombos nas praças e ruas; quantidade de pombos observada dentro de casa/estabelecimento, em números; opinião sobre a quantidade de pombos vista diariamente na região, em categorias: pequena, normal, exagerada e sem opinião; opinião quanto a alimentar estas aves nas praças e ruas); (3) conhecimento sobre zoonoses (se os pombos transmitem doenças, e quais seriam elas); (4) problemas relacionados à presença de pombos (se já teve problemas, quais foram e se foram solucionados; se haviam pombos se alimentando junto com os animais de estimação); (5) ações para redução da população de pombos (quais ações julga adequadas e qual seria o melhor meio de divulgação no caso de uma campanha educativa).

Com uma estimativa de que o prédio histórico UFPR tem aproximadamente 1715 estudantes e servidores e que as praças escolhidas têm 1261 imóveis residenciais e comerciais, foi calculada uma amostragem com 95\% de confiança e $5 \%$ de precisão para população definida. Não existe uma estimativa da população de transeuntes das praças, então, calculou-se uma amostragem com 95\% de confiança e $5 \%$ de precisão para populações infinitas. Desta forma, o número mínimo de questionários foi de 314 estudantes e servidores da UFPR, 294 imóveis residenciais e comerciais e 384 transeuntes.

A aplicação dos questionários foi realizada nos turnos da manhã e da tarde, durante os meses de setembro a novembro de 2012. Os entrevistadores eram alunos do projeto de extensão "Controle de Zoonoses e Educação em Guarda Responsável em Curitiba e Região Metropolitana", do Departamento de Medicina Veterinária da UFPR. Estes alunos foram previamente instruídos e treinados para aplicação dos questionários, para padronização da abordagem e condução do questionário. 


\section{Análise estatística}

A tabulação e tratamento dos dados foi realizada com 0 uso dos softwares Epi Info, versão 7 e SPSS 20.0 (IBM Corp. Released 2011. IBM SPSS Statistics for Windows, Version 20.0. Armonk, NY: IBM Corp.). Associação entre duas variáveis foi verificada com o teste de qui-quadrado ou exato de Fischer, considerando significativo quando $\mathrm{P}<0,05$ e a associação de múltiplas variáveis foi realizada com a análise de correspondência múltipla, com posterior interpretação visual da intensidade das associações.

\section{RESULTADOS}

Foram entrevistados 190 estudantes e servidores, 305 imóveis residenciais e comerciais e 392 transeuntes. A composição da amostra dos estudantes e servidores não contemplou a amostragem mínima pelo fato da universidade não ter uma rotina fixa de servidores e estudantes, apesar das entrevistas terem sido realizadas em horários alternados e em período letivo. Desta forma, foi entrevistado um total de 887 pessoas.

Sobre a presença de pombos no local, a maioria dos entrevistados $533 / 887 \quad(60,1 \%)$, em todas as categorias, foi contra $(\mathrm{P}<0,01)$ (Gráfico 1), não havendo diferença significativa associada à idade $(P=0,06)$. Também em relação ao gênero dos entrevistados, a maioria tanto das mulheres quanto de homens foi contra a presença de pombos (Gráfico 2); porém, a proporção de mulheres contra $(63,4 \%)$ foi significativamente maior do que a proporção de homens $(56,1 \%)(P=0,04)$. No entanto, isto não se deveu ao fato de haverem mais homens a favor, e sim a uma grande parte de homens indiferentes à presença de pombos $(P=0,01)$.
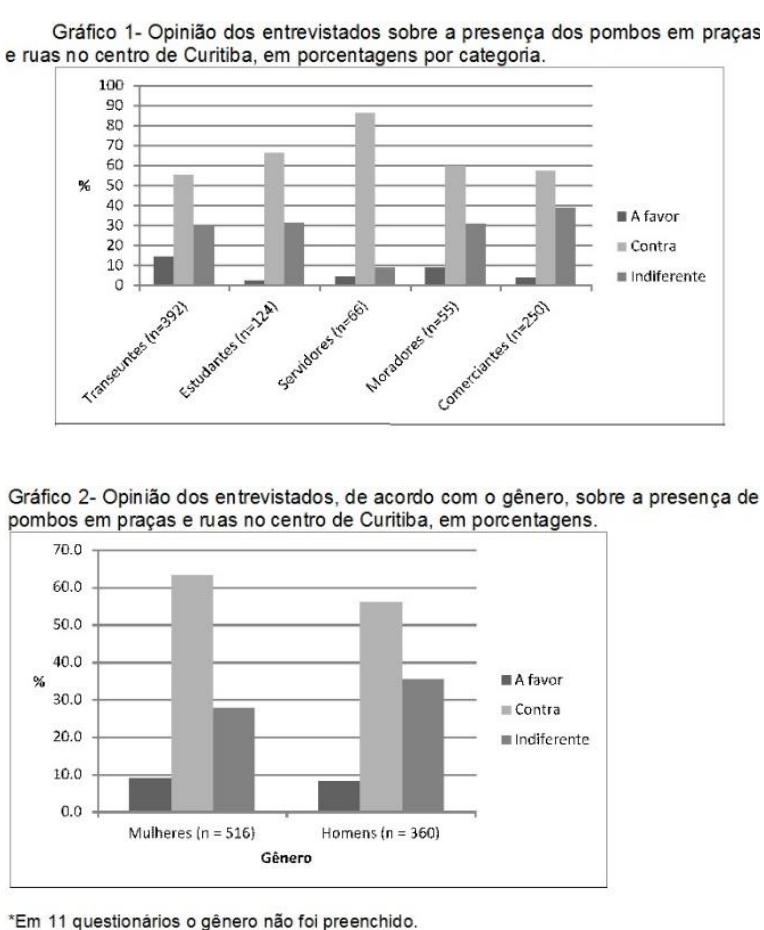

Em relação à profissão dos comerciantes, o tipo de comércio não influenciou na opinião dos mesmos em relação à presença dos pombos, não havendo diferença significativa entre ser a favor, indiferente ou contra $(P=0,29)$.

Quanto à quantidade de pombos na região, a maioria dos entrevistados (617/887, 69,6\%) considerou esta quantidade exagerada $(\mathrm{P}=0,04)$, e destes, 272/617 (44,1\%) atribuíram a alta disponibilidade de alimento como a principal causa $(P<0,01)$. Dentre os $22,0 \%$ (195/887) que consideram normal a quantidade de pombos na região, a principal justificativa foi de que estes animais não interferiam no dia-a-dia do local 61/195 (31,3\%) $(P<0,001)$. Outras causas citadas por este grupo que considerou a quantidade normal foi 0 direito dos pombos de estarem ali $(37 / 195,19,0 \%)$ e equilíbrio natural (29/195, 14,9\%). Dentre os entrevistados que consideraram a quantidade de pombos pequena $(34 / 887,3,8 \%)$, a principal justificativa foi 0 fato dos pombos não incomodarem (9/34 26,5\%), seguida da falta de alimento como causa (6/34, 17,6\%). Para o grupo "sem 
opinião" quanto a quantidade de pombos (40/887, 4,5\%), a maioria foi contra alimentar estas aves nas ruas e praças (34/40, 85,0\%, $\mathrm{P}<0,01)$.

Em relação à quantidade de pombos observada diariamente nas residências, em 23/55 (41,8\%) não eram vistos pombos, em $8 / 55$ (14,5\%) eram vistos de 1 a 5 , em 6/55 (10,9\%) de 6 a 20 , em 10/55 (18,2\%) mais de 20 e em $8 / 55$ residências $(14,5 \%)$ não foi obtida esta informação. Em relação à quantidade de pombos observada diariamente no comércio, em 85/250 $(34,0 \%)$ não eram vistos pombos, em $48 / 250(19,2 \%)$ eram vistos de 1 a 5 , em $47 / 250(18,8 \%)$ de 6 a 20, em 69/250 $(27,6 \%)$ mais de 20 e em $1 / 250$ estabelecimento $(0,4 \%)$ não foi obtida esta informação. Tanto para moradores quanto para comerciantes, independente do número de pombos visto diariamente na residência ou comércio, a percepção de61/108 (56,5\%) sobre a quantidade de pombos na região foi tida como exagerada.

Quando perguntados se os pombos transmitem doenças, $825 / 887$ $(93,0 \%)$ responderam que sim e 62/887 $(6,8 \%)$ que não. Apesar do grande número de respostas afirmativas, mais da metade destes (465/825, 56,4\%), disseram não saber ou não se lembrar que doenças seriam essas. Dos entrevistados que responderam saber quais doenças seriam transmitidas (360/825, 43,6\%), as respostas incluíram nome da doença, sinais clínicos/ sistema acometido ou forma de transmissão (Tabela 1). Alguns entrevistados (76/360, $21,1 \%$ ) citaram mais de uma resposta. As principais respostas foram: doenças respiratórias $(127 / 360,35,3 \%)$, sendo que, $8 / 127 \quad(6,3 \%) \quad$ citaram histoplasmose, $\quad 10 / 360 \quad(2,8 \%)$ criptococose, $82 / 360(22,8 \%)$ piolhos ou pulgas, $\quad 25 / 360 \quad(6,9 \%)$ leptospirose,23/360 (6,4\%) toxoplasmose e 21/360 (5,8\%) citaram doenças em geral transmitidas pelas fezes dos pombos. Outras respostas menos frequentes incluíram doenças de pele, alergias, meningite, raiva, cegueira e fungos.

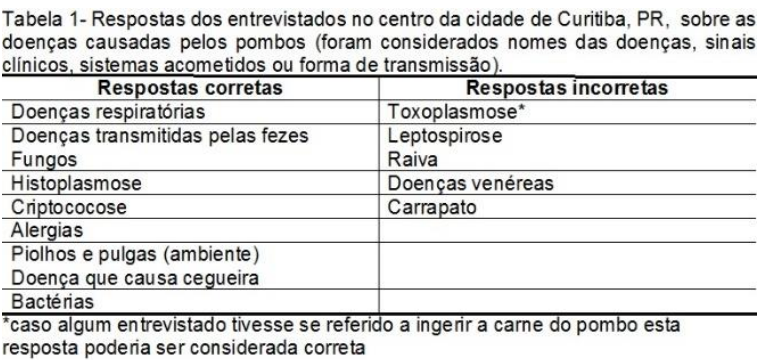

Dentre os que disseram que pombos causam doenças, 528/825 $(64 \%)$ eram contra a presença dos mesmos em ruas e praças, 240/825 $(29,1 \%)$ eram indiferentes e $57 / 825$ $(6,9 \%)$ a favor. O fato de saber ou não que pombos transmitem doenças independeu da faixa etária do entrevistado. Em relação à categoria do entrevistado, $3 / 190 \quad(1,6 \%)$ dos estudantes e servidores, $11,2 \%$ (44/392) dos transeuntes, $5,2 \%(13 / 250)$ dos comerciantes e $3,6 \%$ (2/55) dos moradores responderam que pombos não causam doenças. Quando comparadas categorias, houve diferença entre estudantes e transeuntes $(P<0,01)$, servidores e transeuntes $(p=0,02)$, e comerciantes e transeuntes $(P<0,01)$, sendo que nas três comparações os transeuntes se mostraram mais desinformados sobre os pombos causarem doenças.

Quando perguntados se já tiveram algum problema ocasionado pela presença dos pombos, 202/887 (22,8\%) dos entrevistados disseram que sim. Destes, $116 / 202(57,4 \%)$ relataram que o problema foi ocasionado pela sujeira, $10 / 202(4,9 \%)$ por parasitas de pombos, $11 / 202(5,4 \%)$ por doenças e 9/202 $(4,4 \%)$ pelo barulho, 16/202 (7,9\%) relataram outros problemas como presença de ninhos e ataques/voos dos pombos no rosto das pessoas. A associação de dois ou mais fatores foi 


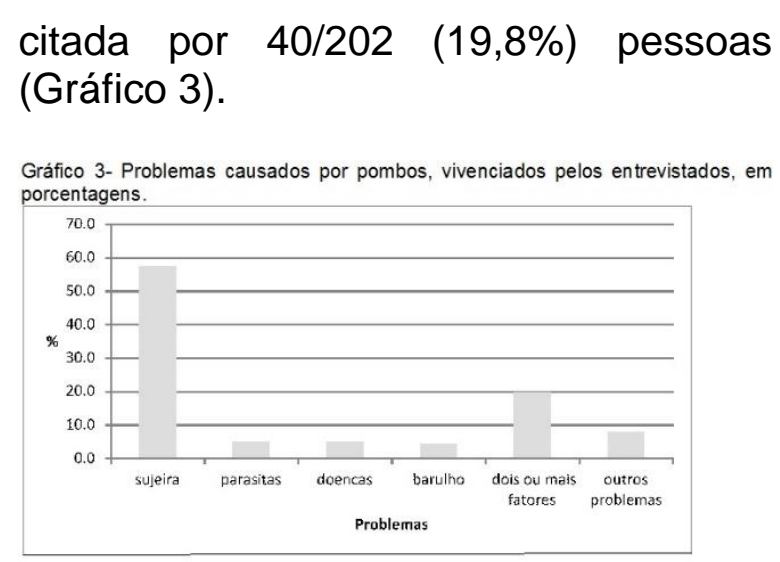

Das pessoas que solicitaram algum tipo de serviço para solucionar o problema (36/202, 17,8\%), $12 / 36$ $(33,3 \%)$ contataram a prefeitura ou 0 CCZV, 9/36 (25\%) procuraram uma dedetizadora, e $15 / 36 \quad(41,7 \%)$ solicitaram os dois serviços ou recorreu a construção de barreira física ou ofícios internos para a própria instituição (no caso dos entrevistados do prédio Histórico). Um total de 23/36 (63,9\%) pessoas conseguiu resolver o problema, sendo solucionado em 9/9 (100\%) dos casos em que se solicitou uma dedetizadora e em 5/12 (41,6\%) dos casos em que solicitou a prefeitura/CCZV. Em relação a ter animais de estimação, 492/887 (55,5\%) responderam que tinham, e destes, $29 / 492$ (5,9\%) afirmaram haver pombos se alimentando junto com seus animais.

Os entrevistados aprovaram a realização de ações para reduzir o número de pombos no ambiente urbano, sendo que 703/887 (79,2\%) aprovou duas ou mais ações em conjunto. As principais ações aprovadas foram impedir pessoas de alimentar os pombos (688/887, 77,6\%), educação da população (617/887, 69,5\%), construção de barreiras físicas $(423 / 887,47,7 \%)$ e uso de anticoncepcionais no alimento dos pombos (394/887, 44,4\%). Ações como atirar nos pombos tiveram poucas aprovações (37/887, 4,2\%).

Foi citado como meio mais eficiente para uma campanha educativa a associação de dois ou mais meios (televisão, internet, panfletos, placas, educação nas escolas, rádio, jornal) (449/887, 50,6\%), e em seguida, a televisão $(273 / 887,30,8 \%)$ como meio único.

A análise de correspondência múltipla foi significativa com a dimensão 1 com 59\% da inércia, tornando válida a representação bidimensional. Desta forma, obteve-se que os homens consideram nenhum dos métodos de divulgação eficientes (TV, rádio, panfletos ou placas de divulgação). As mulheres de 41 a 50 anos consideram anticoncepcional como um método de controle eficiente e que a $\mathrm{TV}$, o rádio, panfletos e placas poderiam ser eficientes na educação. As pessoas que consideram que barreiras físicas podem ser eficientes também consideram educação e não fornecimento de alimentos eficientes. Por fim, assim como encontrado na análise simples, as pessoas contra a presença dos pombos, sabem que os mesmos transmitem doenças e os indiferentes ou a favor não sabem.

\section{DISCUSSÃO}

As zoonoses são responsáveis por um grande número de doenças adquiridas pelo homem, segundo a Organização Mundial de Saúde - OMS, e os pombos podem ser responsáveis pela transmissão de algumas, principalmente através de suas fezes, merecendo atenção como problema de Saúde Pública (Schuller, 2005). Neste estudo verificou-se que a maioria da população era contra a presença de pombos em todas as categorias de entrevistados. A maior proporção de indiferentes se deu na categoria de comerciantes, sendo um fato não esperado, já que a presença dos pombos supostamente estaria afetando 0 comércio, devido a sujeira e ao risco de doenças, principalmente em comércio 
relacionado a saúde (por exemplo farmácias), e comércio de venda de alimento.

Em relação ao gênero do entrevistado, independente da categoria, foi significativa a proporção de mulheres contra em relação a proporção de homens, além da percepção masculina sobre métodos eficazes ser contrária à feminina. De forma geral, de acordo com as questões abordadas neste estudo, a população humana se mostrou incomodada com a superpopulação de pombos e suas consequências, e acreditam que os problemas dependem da atitude de cada cidadão. A despeito disso, existe um comportamento paradoxal no sentimento das pessoas em relação a estas aves. De forma positiva, os pombos são considerados belos e meigos, além de seu significado cultural e religioso, visto como mensageiro (fazendo alusão à seu uso como pombo-correio), símbolo do Espírito Santo, de fidelidade e do amor eterno, além de seu papel de ornamentação em parques e praças (Rodrigues, 2009; Méndez Mancera et al., 2013). atração turística e maior contato com a natureza (Ramírez et al., 2008). Desta forma, muitas pessoas costumam alimentá-los para manter um vínculo baseado nestas simbologias, e também por questões humanitárias, por receio que os pombos possam morrer de fome (Weber et al., 1994; Rodrigues et al., 2009), e também por diversão, principalmente na companhia de crianças. No caso de algumas pessoas, alimentar os pombos implica em ter alguma atividade, por carência e para aliviar a solidão (Weber et al., 1994).

Observou-se que a população tem o conceito de que os pombos transmitem doenças, apesar de que a maioria não saiba dizer que doenças são estas. Para os entrevistados que disseram saber as doenças transmitidas, mais da metade respondeu de forma correta, com o nome da doença e/ou seus sinais clínicos.
Porém, algumas pessoas se mostraram desinformadas ou equivocadas, relacionando o pombo à transmissão de toxoplasmose (que seria possível apenas se a ave fosse ingerida, uma vez que poderia ter bradizoítos em sua musculatura), leptospirose e raiva (para estas duas últimas não há relatos de transmissão por aves). Dados semelhantes foram encontrados em pesquisa em Santos/SP e São Paulo/SP, na qual $95,8 \%$ dos entrevistados afirmaram que pombos transmitem doenças, sendo que alguns também citaram doenças como leptospirose, peste bubônica ou raiva como sendo transmitidas por pombos (Miranda et al., 2014). Em estudo em um parque de São Paulo, os resultados também foram semelhantes, com a maioria citando doenças transmitidas por pombos, porém com algumas pessoas apontando doenças como AIDS, câncer e infarto como sendo causadas por pombos2. A semelhança entre as respostas nos três estudos pode sugerir que esta seja uma percepção geral da população brasileira. Enquanto a consciência do risco de doença zoonótica é um pré-requisito para uma prevenção eficaz, o conhecimento limitado das zoonoses por parte da população é uma preocupação (Stull et al., 2012), sendo um dos pilares importantes para políticas públicas.

O fato dos transeuntes se mostrarem mais desinformados em relação às doenças transmitidas pelos pombos, em relação a outras categorias de entrevistados (estudantes, servidores e comerciantes) pode se dever ao fato desta categoria ser mais heterogênea em níveis socioculturais, porém a baixa amostragem para algumas categorias também deve ser considerada.

Além de problemas higiênicos e sanitários, os pombos podem causar danos ao defecarem em patrimônios históricos, degradando a arquitetura original (Bencke, 2007). O acúmulo de fezes e de sujeira ocorre principalmente 
em locais perto de seus abrigos como praças, casas e locais com arquitetura mais antiga como universidades, hospitais e igrejas Sacchi et al., 2002). No presente relato, o principal problema sofrido pela população foi decorrente da sujeira causada pelos pombos, porém outros problemas foram relatados, como doenças e aves voando próximas ao rosto das pessoas. Alguns problemas citados na literatura são menos comuns, porém podem ser graves, como acidentes de trânsito (Visordown, 2011; Globo Minas, 2011) ou com grande prejuízo à sociedade, como curtocircuitos (Super Informado, 2011). Da mesma forma, em grandes infestações de ambientes por ectoparasitas pode se fazer necessária a evacuação do local e dedetização, como ocorrido em um hospital em 2008 (Gazeta do Povo, 2008) e no prédio histórico da Universidade Federal do Paraná, localizado no centro da cidade, no ano de 2012 (Paraná Online, 2012).

Para o controle da população de pombos nos centros urbanos, devem ser adotadas medidas já sabidamente efetivas, permitidas pela legislação e que estejam de acordo com os meios aprovados pela população. Desta forma, as medidas que se enquadrariam nestas condições seriam a construção de barreiras físicas e evitar a disponibilidade de alimentos através da educação da população. Em estudos realizados no Brasil e em outros países, já foi demonstrado que a supressão das fontes de alimentação alternativa reduz significativamente o número de pombos em um curto espaço de tempo (Nunes, 2003), sendo apenas dependente da educação da população e de ações (da sociedade e do governo) para evitar o acúmulo de lixo nas ruas.

Ainda de acordo com a população entrevistada, para uma campanha educativa, a televisão isoladamente, ou sua associação com outros meios de comunicação seriam os mais efetivos.
Para campanhas governamentais, devese levar em consideração os custos, a efetividade e também a poluição ambiental ou visual (no caso de panfletos ou placas). Alguns meios são facilmente divulgados, como internet e televisão, e outros, apesar de requerem uma equipe com trabalho permanente, como a educação infantil nas escolas abordando o tema zoonoses (Moraes, 2013), devem ser considerados, pois as crianças se apresentam mais abertas a mudanças, questionamentos e atitudes. Através do trabalho em escolas, ao longo do tempo, pode-se formar uma grande parcela da população capacitada para a prática da prevenção de doenças, diminuindo os gastos da rede pública com tratamentos em Unidades de Atenção Básica de Saúde e Hospitais Públicos (Moraes, 2013). É importante ressaltar que o controle de pombos nas cidades visa a redução do número destas aves sem a sua eliminação total, visando um equilíbrio entre ambiente urbano e animais, não devendo ser meta um ambiente "abiota" (Biondo et al., 2014).

A percepção da população sobre a presença de pombos no ambiente urbano e o conhecimento acerca dos danos causados por esta alta densidade populacional de aves é importante para que políticas públicas para a redução do número de pombos seja efetiva, incluindo medidas em relação ao ambiente e educação da população.

\section{CONCLUSÃO}

O presente estudo demonstrou que as pessoas em contato com pombos no centro urbano são contra a presença dos mesmos nestes ambientes, sabem que podem trazer agravos (transmissão de doenças e acúmulo de lixo, principalmente) e acreditam que 0 melhor meio de controlar a população de pombos é por meio de educação, construindo barreiras físicas e evitando o 
fornecimento de alimentos aos animais nestes ambientes.

\section{REFERÊNCIAS}

ASSOCIAÇÃO COMERCIAL E INDUSTRIAL DE LONDRINA - ACIL. Doença de pombo causa morte de taxista. 2013; 24 mar. Acessado em 2014 jun 26. Disponível em: http://www.acil.com.br/noticias-

detalhe/25/03/2013/doenca-do-pombo-causamorte-de-taxista.

BENCKE, G.A. Pombos-domésticos: sugestões para o controle em escolas públicas estaduais de Porto Alegre. Porto Alegre: Museu de Ciências Naturais/FZB-RS e 1ㄹ CRE/SE, 2007. 22p.

BIONDO, A.W.; AFONSO, J.A.C.; MOURA, R.R. et al. A cidade sem seus bichos: a biofobia cosmopolita e seu impacto na fauna urbana. Clínica Veterinária (São Paulo), v.19, n.110, p.34-38, 2014.

BONNEFOY, X., KAMPEN, H., SWEENEY, K. Public health significance of urban pests. Copenhagen: World Health Organization, 2008. 569p.

BRAGA, K.F.; RIBEIRO, J.; STAUDACHER, C. et al. Registro de fauna sinantrópica no Centro de Controle de Zoonoses de Curitiba e medidas para monitoramento. In: 18ำ Evento de Iniciação Científica e $2^{\circ}$ Evento de Iniciação em Desenvolvimento Tecnológico e Inovação Universidade Federal do Paraná; 2009; Curitiba. Anais... Curitiba: UFPR, 2009.

CONSELHO REGIONAL DE MEDICINA VETERINÁRIA PR- CRMV PR. Doença do pombo faz vítima fatal em Londrina., 2008; 14 jan. Acessado em 2014 jun 26. Disponível em: http://www.crmv-

pr.org.br/?p=imprensa/noticia_detalhes\&id=1137

COORDENAÇÃO DE CONTROLE DE ZOONOSES E VETORES PREFEITURA MUNICIPAL DE CURITIBA- CCZV. Pombos. Boletim informativo. [Acessado $2013 \mathrm{dez}$ 10] Disponível em: http://www.saude.curitiba.pr.gov.br/index.php/vig ilancia/saude-ambiental/zoonoses-e-vetores.

COSTA, A.K.; SIDRIM, J.J.; CORDEIRO, R.A. et al. Urban pigeons (Columba livia) as a potential source of pathogenic yeasts: a focus on antifungal susceptibility of Cryptococcus strains in Northeast Brazil. Mycopathologia, v.169, n.3, p.207-213, 2010.
DICKX, V.; BEECKMAN, D.S.A.; DOSSCHE, L. et al. Chlamydophila psittaci in homing and feral pigeons and zoonotic transmission. Journal of Medical Microbiology, v.59, n.11, p.1348-1353, 2010.

FARIA, R.O.; NASCENTE, O.S.; MEINERZ, A.R.M. et al. Ocorrência de Cryptococcus neoformans em excretas de pombos na Cidade de Pelotas, Estado do Rio Grande do Sul. Revista da Sociedade Brasileira de Medicina Tropical, v.43, n.2, 2010.

GAZETA DO POVO. Piolhos interditam ala do Cajuru. Vida e cidadania. 2008. Disponível em: <http://www.gazetadopovo.com.br/vidaecidadani a/conteudo. . phtml?id=814350 $>$. Acesso em 26 junho 2014.

GEIGENFEIND, I.; VANROMPAY, D.; HAAGWACKERNAGEL, D. Prevalence of Chlamydia psittaci in the feral pigeon population of Basel, Switzerland. Journal of Medical Microbiology, v.61, n.2, p.261-265, 2012.

GLOBO MINAS. Pombo invade carro e provoca acidente em avenida de BH. 2011; 2 dez. [Acessado 2014 jun 26]. Disponível em: http://g1.globo.com/minas-

gerais/noticia/2011/12/pombo-invade-carro-eprovoca-acidente-em-avenida-de-bh.html.

GONZÁLEZ-ACUÑA, D.; SILVA, G.F.; MORENO, S.L. et al. Detección de algunos agentes zoonóticos en la paloma doméstica (Columba livia) en la ciudad de Chillán, Chile. Revista Chilena de Infectología, v.24, n.3, p.199203, 2007.

HAAG-WACKERNAGEL, D.; SPIEWAK, R. Human infestation by pigeon fleas (Ceratophyllus columbae) from feral pigeons. Annals of Agricultural and Environmental Medicine, v.11, n.2, p.343-346, 2004.

LIMA, V.Y.; LANGONI, H.; SILVA, A.V. et al. Chlamydophila psittaci and Toxoplasma gondii infection in pigeons (Columba livia) from São Paulo state, Brazil. Veterinary Parasitology, v.175, n.1-2, p.9-14, 2011.

MÉNDEZ MANCERA, V.M.; JIMÉNEZ, L.C.V.; MEDINA, D.A.B. et al. La paloma (Columba livia) en la transmisión de enfermedades de importancia en salud pública. Revista Ciencia Animal, [S.I.], n. 6, p. 177-194, 2013.

MIRANDA, C.; LADENDORFF, N.; KNÖBL T. Percepção da população sobre a participação dos pombos (Columba livia domestica) na transmissão de zoonoses. Atas Saúde Ambiental-ASA, v.2, n.1, p.23-28, 2014.

MORAES, F.C. Educação em saúde: formação de Multiplicadores em zoonoses e guarda 
responsável de animais de estimação. 2013. Jaboticabal, 56f. Dissertação(Mestrado em Medicina Veterinária) -Curso de Pós-graduação em Medicina Veterinária, Universidade Estadual de São Paulo- Campus Jaboticabal.

NUNES, V.F.P. Pombos urbanos: o desafio de controle. O Biológico, v.65, n.1, p. 89-92, 2003.

PARANÁ ONLINE. População deve parar de alimentar pombos. 2012; 20 mar. [Acessado 2014 jun 26]. Disponível em: <http://www. paranaonline.com.br/editoria/cidades/news/600195/?no ticia=POPULACAO+DEVE+PARAR+DE+ALIME NTAR+POMBOS

RAMÍREZ, O.; AMADOR, M.; CAMACHO, L. et al. Conocimiento Popular de la Paloma de Castilla (Columba livia) en el Parque Central de Alajuela. Zeledonia, v.12, n.1, p.14-19. 2008.

ROCHA-E-SILVA, R.C.; MACIEL, W.C.; TEIXEIRA, R.S.C. et al. O pombo (Columba livia) como agente carreador de Salmonella spp. e as implicações em saúde pública. Arquivos do Instituto Biológico, v.81, n.2, p.189-194, 2014.

RODRIGUES, J.G.; ESTON, M.R.; MARCONDES, M.A. et al. A Percepção dos visitantes do Parque Estadual Alberto Löfgren São Paulo Em Relação à Presença de Pombos Domésticos Columba livia domestica Como Vetores de Zoonoses. In: III Seminário de Iniciação Científica do Instituto Florestal; 2009; São Paulo. Anais... São Paulo: Secretaria do Meio Ambiente, 2009, p. 155-160.

SACCHI, R.; GENTILLI, A.; RAZZETTI, E. et al. Effects of building features on density and flock distribution of feral pigeons Columba livia var. domestica in an urban environment. Canadian Journal of Zoology, v.80, n.1, p.48-54, 2002.

SCHULLER, M. Pombos urbanos - um caso de saúde pública. Sociedade Brasileira de Controle de Contaminação, v.29, p.32-37. 2005.

SGUARIZI, G. Fauna Sinantrópica: Convivência e Consciência. Revista CFMV-PR, v.5, n.23, p.14-15. 2007.

SILVA, J.O.; CAPUANO, D.M. Ocorrência de Cryptococcus spp e de parasitas de interesse em saúde pública, nos excretas de pombos na cidade de Ribeirão Preto, São Paulo, Brasil. Revista do Instituto Adolfo Lutz, v. 67, n. 2, p.137141, 2008.

STULL, J.W.; PEREGRINE, A.S.; SARGEANT, J.M. et al. Household knowledge, attitudes and practices related to pet contact and associated zoonoses in Ontario, Canada. BMC Public Health v.12, n.1, p.553, 2012.

SUPER INFORMADO. Pombo deixa $10 \mathrm{mil}$ unidades do centro de Curitiba sem luz. 2011; 24 nov. [Acessado 2014 jun 26]. Disponível em: http://www.superinformado.com.br/noticias-doparana/pombo-deixa-10-mil-unidades-do-centrode-curitiba-sem-luz/

VISORDOWN. Rider survives $140 \mathrm{mph}$ pigeon crash. 2011; 1 sept. [Acessado 2014 jun 26] Disponível em: www.visordown.com/motorcyclenews-bizarre/rider-survives-140mph-pigeoncrash/18919.html

WEBER, J.; HAAG, D.; DURRER, H. Interaction between humans and pigeons. Anthrozoös, v.7, n.1, p.55-59, 1994. 